ARTIGO

Recebido em: 29/09/2017

Aceito em: $25 / 06 / 2018$

\title{
Produção científica brasileira em organização e representação da informação: estudo bibliométrico nos periódicos Qualis A
}

\author{
Brazilian scientific production in organization and representation \\ of information: bibliometric study in Qualis A periodics
}

\begin{tabular}{c} 
Odete Máyra Mesquita SALES (mayra.mesquita@gmail.com) * \\
Sale Mário GAUDÊNCIO (salemario@gmail.com) ${ }^{* *}$ \\
Dulce Amélia de Brito NEVES ( $\underline{\text { damelia1@gmail.com) }})^{* * *}$ \\
* Doutoranda do Programa de Pós-graduação em Ciência da Informação pela Universidade Federal da \\
Paraíba e Professora do Departamento de Ciências da Informação da Universidade Federal do Ceará. \\
** Doutorando do Programa de Pós-graduação em Ciência da Informação pela Universidade Federal \\
da Paraíba e Bibliotecário-Documentalista da Universidade Federal Rural do Semi-Árido (UFERSA). \\
*** Professora da Universidade Federal da Paraíba e do Programa de Pós-graduação em Ciência da \\
Informação - PPGCI. \\
\hline
\end{tabular}

\section{Resumo}

A pesquisa objetiva identificar, nos periódicos científicos com maior Qualis (estratos A1 e A2), a produção científica brasileira sobre a temática da Organização e Representação da Informação publicada na área da Ciência da Informação no período de 2007 a 2016 (últimos 10 anos) Metodologicamente, a coleta e a análise dos dados foram basiladas por meio de um estudo bibliométrico. Como resultados, foi percebido que, dentre os periódicos nacionais e internacionais, temos uma produção científica "doméstica". Percebeu-se que as principais revistas que publicam pesquisas no campo da temática "Organização e Representação da Informação", foram: a) Informação \& Informação (UEL); b) Encontros Bibli (UFSC); e c) Transinformação (PUC-Campinas). A pesquisa mostra, também, que os autores mais representativos quantitativamente, em número de publicações, escrevem em sua maioria em colaboração.

Palavras-chave: Organização da informação. Representação da informação. Bibliometria. Periódicos científicos. Qualis.

\section{Abstract}

The research aims to identify, in the scientific journals with the highest Qualis (strata A1 and A2), the Brazilian scientific production on the topic of Organization and Representation of Information published in the area of Information Science from 2007 to 2016 (last 10 years). Methodologically, the collection and analysis of the data were based on a bibliometric study. As a result, it was noticed that, among national and international journals, we have a "domestic" scientific production. It was noticed that the main magazines that publish researches in the field of "Organization and Representation of Information", were: a) Information \& Information (UEL); b) Encontros Bibli (UFSC); and c) Transinformação (PUC-Campinas). Research shows that the most representative authors quantitatively, in number of publications, write mostly in collaboration.

Keywords: Organization of information. Representation of information. Bibliometric. Scientific journals. Qualis.

v. 23, n. $53,2018$. p. $16-24$ 


\section{INTRODUÇÃO}

A temática da Organização e Representação da Informação, no campo da Ciência da Informação (CI), sempre esteve associada aos processos de produção e armazenamento da informação com vistas à sua recuperação, acesso e uso (SANTOS; NEVES; FREIRE, 2017). Logo, o assunto em lide se reveste de interesse particular para a CI, tanto no aspecto do ensino, como no aspecto da pesquisa.

Partindo dessa premissa, consideramos indispensável verificar como essa temática vem sendo difundida nas produções científicas, por meio de um estudo bibliométrico pautado na importância de se conhecer e avaliar a produtividade sobre o tema, identificando os autores e pesquisadores, bem como verificando os padrões da atividade científica publicada em âmbito nacional e internacional. Souza (2013, p. 20) afirma que "os estudos bibliométricos têm sido cada vez mais requisitados e utilizados para a quantificação da produção e também para outras finalidades, como identificar grupos e áreas de excelência acadêmica".

Nessa perspectiva, empreendemos esta pesquisa com o objetivo de identificar, nos periódicos científicos com maior Qualis (estratos A1 e A2), a produção científica brasileira sobre a temática da Organização e Representação da Informação, publicada na área da CI, no período de 2007 a 2016.

Esta pesquisa surgiu a partir das questões teóricas provocadas pela disciplina de Organização, Acesso e Uso da Informação, ofertada pelo Programa de Pós-Graduação em Ciência da Informação da Universidade Federal da Paraíba.

\section{ORGANIZAÇÃO E REPRESENTAÇÃO DA INFORMAÇÃo}

Pensada sob um prisma global, a representação é o elemento central da existência da humanidade, já que "desde o princípio das civilizações, o ser humano utiliza diversos recursos para simbolizar a realidade que o circunda", conforme explicitam Lima e Alvares (2012, p. 21). Esta civilização está condicionada à necessidade de representar, tenha isso um viés positivo ou negativo.

Para representar algo sob um plano horizontalizado, nos dias atuais, potencializamse aos mais diversos atores sociais, dentre outras coisas, criar rótulos, motivar preconceitos, influenciar os modelos de sociedades, ser complacente às políticas impopulares, etc.

Nesse mesmo contexto, e sob uma perspectiva aplicada, a representação face ao contexto da organização da informação parte do princípio de "estar no lugar de...", coadunando com o que Alvarenga (2003, p. 20) já explicitava no início do século XXI, que "representar significa o ato de colocar algo no lugar de". Ou seja, é um rito de passagem, de migração cognitiva ou de tradução, da linguagem natural para a artificial.

É a potência informacional de fazer entender que uma "coisa X", com sua peculiar força física, passa a ideia de outra, que foi legitimamente convencionada semanticamente e aceita mentalmente por uma dinâmica social e cultural, estabelecendo que aquela "coisa X" é ou representa uma convenção mental para tratar a "coisa Y". Tem-se, assim, um processo contínuo de "ressignificação informacional" (GAUDÊNCIO, 2017), onde um fenômeno assume o lugar de outro, contribuindo para modelos de linguagens dinâmicas e relevantes ao rito de sua construção cognitiva.

Imbuídos por essa assertiva, é possível perceber o quanto esse campo é relevante, pois desde a percepção do seu enquadramento para responder às demandas expostas pelos objetos físicos, passando pela sua importância semântica e cognitiva até o fato de reconhecer e respeitar o meio ambiente social, infere-se que desde o início da civilização, passando pelos postulados acadêmicos até a sua aplicação científica, tem-se consolidado a ideia de um campo de domínio sólido e central, não apenas a Biblioteconomia e a Ciência da Informação, mas essencialmente a ciência.

A representação, enquanto subcampo disciplinar, é muitas vezes confundida com o próprio campo, ou seja, a organização da informação. Com o avanço das iniciativas de Pesquisa, Desenvolvimento e Inovação (PD\&I), uma série de novas demandas começou a compor e a adicionar investigações científicas ao "guarda-chuva" deste campo. Basta observar as pesquisas sobre ações adicionais ou modelos contemporâneos de representação da informação. A exemplo disso, estão as investigações teóricas e metodológicas a partir da semântica discursiva, protocolo verbal, prontuário eletrônico, análise de rede em mídia digital, curadoria digital, métricas informacionais (bibliometria, cientometria e webometria). 
Apesar do avanço de outras áreas de domínio no campo da Ciência da Informação, a representação da informação, através do processo de organização, continua sendo uma disciplina extremamente relevante, basta observar e visualizar o direcionamento e a valorização investigativa e científica que lhe é dada pela Associação Nacional de Pesquisa e Pós-Graduação em Ciência da Informação (ENANCIB) no plano local, assim como através da International Society for Knowledge Organization (ISKO), no contexto global.

A partir desse cenário, oportuniza-se a possibilidade de monitoramento da produção científica da Ciência da Informação a partir das investigações em organização da informação e, a partir dela, da dinâmica de representação informacional.

\section{PROCEDIMENTOS METODOLÓGICOS}

Para a elaboração e execução da pesquisa, foi escolhido o método bibliométrico. Conforme Bufrem e Prates (2005, p.11), a bibliometria busca "um perfil dos registros do conhecimento, servindo-se de um método quantificável, para gerar informações que mapeiam o desenvolvimento da produção científica". Nesse entendimento, o processo investigativo foi dimensionado considerando inicialmente as condições quantitativas dos fenômenos em estudo.

A presente pesquisa configura-se como um estudo de caráter descritivo e exploratório. Descritiva por considerar que "[...] têm como objetivo primordial à descrição das características de determinada população ou fenômeno ou o estabelecimento de relações entre variáveis" (GIL, 2014, p. 28). Exploratória por entender que "[...] se caracteriza pelo desenvolvimento e esclarecimento de ideias, com objetivo de oferecer uma visão panorâmica, uma primeira aproximação a um determinado fenômeno [...]" (GONSALVES, 2011, p. 67).

É privilegiado nesta pesquisa um enfoque quantitativo, que segundo Sampieri, Collado e Lucio (2013, p. 30) trata-se de um processo "sequencial e comprobatório". Isso se dá por perceber que "necessitamos de conhecimento e capacitação para compreendermos informações numéricas produzidas por outros, bem como nos habilitarmos a construí-las". (MARTINS; THEÓPHILO, 2009, p. 108).

O corpus investigativo "não está interessado em estudar indivíduos isolados ou casos particulares. Seu objetivo é, antes, estabelecer generalizações, a partir de observações em grupos ou conjunto de indivíduos [...]" (RUDIO, 2012, p. 60). Assim, o corpus da pesquisa foi formado por artigos publicados no período de janeiro de 2007 a dezembro de 2016, em periódicos científicos nacionais e internacionais disponíveis on-line da área de Ciência da Informação, que receberam os estratos A1 e A2, na Classificação Qualis Periódicos Quadriênio 2013-2016, pela Coordenação de Aperfeiçoamento de Pessoal de Nível Superior (Capes). A escolha por esse estrato se dá pela credibilidade das publicações que conferem qualidade aos conteúdos disponíveis e aspectos como fator de impacto (relacionado ao índice de citaç̃os), corpo editorial, regularidade e indexação de títulos em bases de dados (MENDONÇA, 2015).

Ao favorecer um delineamento mensurável da pesquisa, "[...] a coleta de dados ocorre após a definição clara e precisa do tema-problema, composição da plataforma teórica, abordagem metodológica definida, [...]" (MARTINS; THEÓPHILO, 2009, p. 85). Com isso, "o pesquisador-autor poderá dar mais ênfase à avaliação quantitativa, e assim procurará mensurar, ou medir, variáveis". Neste sentido, a coleta de dados foi realizada por meio da navegação nos arquivos dos periódicos digitais on-line. Para a seleção da amostra, foram considerados artigos que apresentaram no título, no resumo ou nas palavras-chave os termos de buscas: organização da informação e representação da informação.

0 processo de análise dos dados se deu considerando a técnica da tabulação, que na visão de Gil (2014, p. 158), trata do "processo de agrupar e contar os casos que estão nas várias categorias de análise". Neste sentido, com os resultados obtidos, a análise se deu com base nos critérios determinados de caráter geral, que incluíam: periódicos, número de artigos, anos de publicação e autorias, que averiguaram: tipo de autoria e quantidade de artigos por autor. Para análise e apresentação dos resultados, foi criada uma planilha na qual foram inseridas as principais informações sobre os artigos. Acrescentaram-se, ainda, colunas para uma melhor organização dos dados. Em seguida, transformou-se os dados da planilha em gráficos e tabelas para um melhor entendimento dos resultados. 


\section{RESULTADOS E DISCUSSÃO}

A classificação Qualis Periódico - Quadriênio 2013-2016 apresenta, na área de avaliação Comunicação e Informação, a qual engloba o campo da Ciência da Informação, 18 periódicos com estrato A1 e A2. Após a identificação dos periódicos, conseguimos coletar 88 artigos referentes ao intervalo de 2007 a 2016, os quais foram analisados e apresentados.

A partir dos dados coletados, criou-se o Quadro 1 para facilitar a compreensão e a análise das publicações recuperadas nas bases de dados dos periódicos científicos levantados. É possível observar a distribuição de artigos por periódicos, Qualis e ano de publicação.

Quadro 1: Quantidade de publicações por periódico e ano (nacional e internacional)

\begin{tabular}{|c|c|c|c|c|c|c|c|c|c|c|c|c|}
\hline PERIÓDICO & QUALIS & $\begin{array}{l}2 \\
0 \\
0 \\
7\end{array}$ & $\begin{array}{l}2 \\
0 \\
0 \\
8\end{array}$ & \begin{tabular}{l|l|}
2 & \\
0 & \\
0 & \\
9 &
\end{tabular} & $\begin{array}{l}2 \\
0 \\
1 \\
0\end{array}$ & $\begin{array}{l}2 \\
0 \\
1 \\
1\end{array}$ & $\begin{array}{l}2 \\
0 \\
1 \\
2\end{array}$ & $\begin{array}{l}2 \\
0 \\
1 \\
3\end{array}$ & $\begin{array}{l}2 \\
0 \\
1 \\
4\end{array}$ & $\begin{array}{l}2 \\
0 \\
1 \\
5\end{array}$ & $\begin{array}{l}2 \\
0 \\
1 \\
6\end{array}$ & TOTAL \\
\hline Informação \& Sociedade & \multirow{12}{*}{ A1 } & 2 & 2 & & & & 1 & & 1 & & 1 & 7 \\
\hline $\begin{array}{l}\text { Perspectivas em Ciência da } \\
\text { Informação }\end{array}$ & & & & 1 & 1 & 1 & & 4 & & & & 7 \\
\hline Transinformação & & 1 & 1 & 1 & 2 & & & & 1 & & 3 & 9 \\
\hline Biblios (Lima) & & & & & & 1 & & 1 & 2 & 1 & 1 & 6 \\
\hline El Profesional de la Información & & 1 & & & & 1 & & & & & & 2 \\
\hline Information Research & & 1 & & & 1 & & & & & & 1 & 3 \\
\hline Journal of Documentation & & & & & & & & 2 & & & & 2 \\
\hline $\begin{array}{l}\text { Journal of Librarianship and } \\
\text { Information Science }\end{array}$ & & & & & & 1 & & & & & & 1 \\
\hline Information Sciences & & & & & & & & & & & & $\mathbf{0}$ \\
\hline Investigación Bibliotecológica & & & & & & & & & & & & $\mathbf{0}$ \\
\hline $\begin{array}{l}\text { Journal of the American Society } \\
\text { for Information Science and } \\
\text { Technology }\end{array}$ & & & & & & & & & & & & $\mathbf{0}$ \\
\hline Knowledge Organization & & & & & & & & & & & & $\mathbf{0}$ \\
\hline Anales de Documentación & \multirow{6}{*}{ A2 } & 1 & & & & 1 & & & & & & 2 \\
\hline Em Questão & & & & & 1 & & & & 1 & 1 & 2 & 5 \\
\hline Encontros Bibli & & 1 & 3 & & 1 & 2 & 7 & 1 & & & 2 & 17 \\
\hline Informação \& Informação & & 2 & 1 & 3 & 2 & 3 & 2 & 2 & 3 & 4 & 2 & 24 \\
\hline $\begin{array}{l}\text { Revista Interamericana de } \\
\text { Bibliotecologia }\end{array}$ & & 1 & & & & & 1 & & & & 1 & 3 \\
\hline $\begin{array}{l}\text { Revista General de Información y } \\
\text { Documentación }\end{array}$ & & & & & & & & & & & & $\mathbf{0}$ \\
\hline TOTAL & & 10 & 7 & 5 & 8 & 10 & 11 & 10 & 8 & 6 & 13 & 88 \\
\hline
\end{tabular}

Fonte: Dados da pesquisa (2017)

De acordo com os dados apresentados no quadro acima, podemos verificar que dos 18 periódicos, cinco não publicaram nenhum artigo sobre a temática Organização da Informação e/ou Representação da Informação. Observamos, ainda, que esses cinco são periódicos internacionais que são publicados, predominantemente, nos idiomas inglês e espanhol. Por meio das buscas na base de dados desses periódicos, foi possível notar que prevalecem as publicações que abordam temáticas sobre Organização e Representação do Conhecimento, que possuem foco diferente do que buscamos na pesquisa, pois, de acordo com o entendimento de Brascher e Café (2008, p. 8), essa temática aborda o mundo dos conceitos, tratando-se de um processo que tem por base "a análise do conceito e de suas características para o estabelecimento da posição que cada conceito ocupa num determinado domínio, bem como das suas relações com os demais conceitos que compõem esse sistema nocional".

Diante do quadro exposto, inferimos que existe certa predominância de publicações no âmbito nacional. 0 Gráfico 1 apresenta, por periódico, a quantidade de publicações que foram coletadas entre os anos 2007 a 2016. 


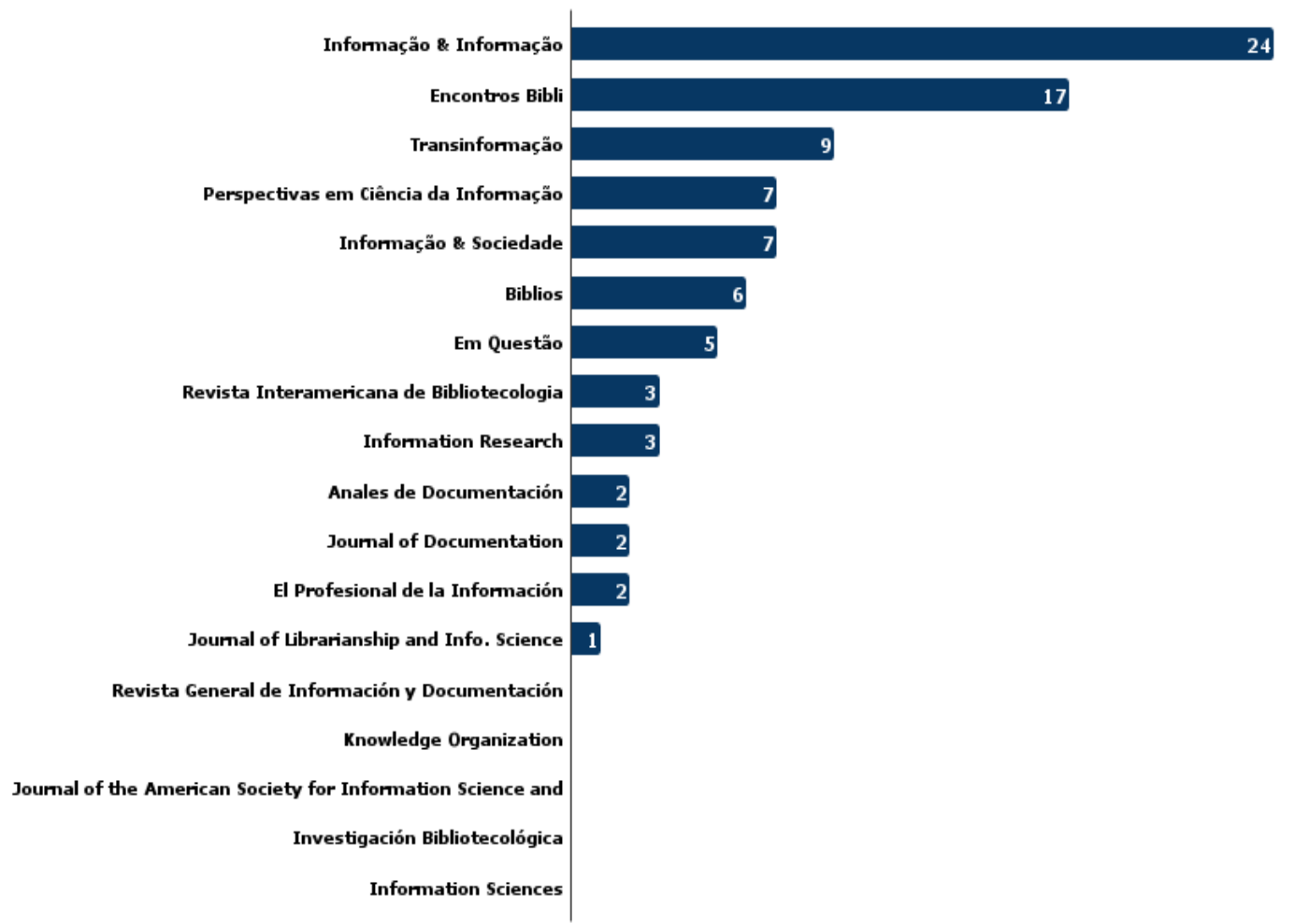

Gráfico 1: Quantidade de artigo por periódico.

Fonte: Dados da pesquisa (2017)

Observa-se que as revistas Informação \& Informação, Encontros Bibli e Transinformação publicaram respectivamente 24, 17 e 9 artigos sobre a temática em lide. Esses dados reforçam nossa conclusão de que existem mais publicações nos periódicos nacionais.

Dentre os fatos que reforçam essa ideia estão o das publicações especiais, por exemplo, o periódico Informação \& Informação, que durante o ano de 2011, apresentou um volume especial intitulado "Conceitos na Organização e Representação do Conhecimento", o que contribuiu para que ele ficasse em primeiro lugar entre os periódicos selecionados, pois alguns artigos tinham no resumo e nas palavras-chave os termos "organização da informação" e "representação da informação".

O periódico científico Encontros Bibli, no recorte temporal selecionado, publicou nove números especiais. Apesar desses números não terem como foco principal a temática estudada (Organização e Representação da Informação), alguns artigos contemplavam o assunto e por conta disso, o periódico ficou entre os três que reuniram mais publicações durante esses dez anos.

A distribuição dos 88 artigos científicos referentes ao recorte temporal entre os anos de 2007 a 2016 estão representados no Gráfico 2. 


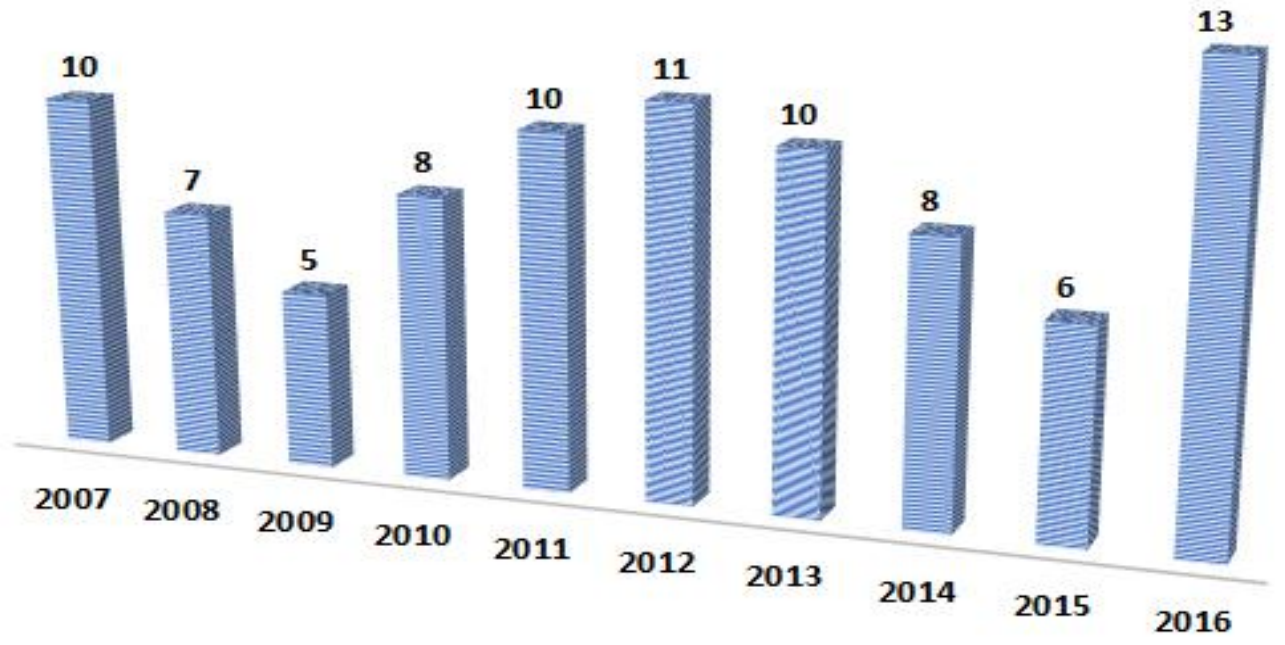

Gráfico2: Quantidade de artigo por ano.

Fonte: Dados da pesquisa (2017)

0 Gráfico 2 representa a dinâmica temporal da produção de artigos. Nela, percebe-se uma considerável queda nas publicações sobre a temática em lide nos anos de 2008 e 2009. A partir de 2010 até 2013, é apresentado aumento seguido de um comportamento relativamente estável, porém tem-se novamente um declínio nos anos de 2014 e 2015, voltando a crescer em 2016. A média de publicações entre esses dez anos foi de 8,8 artigos por ano. Observa-se que a quantificação da produção de artigos apresentou oscilações entre crescimento e queda durante os dez anos analisados.

Outro aspecto que observamos nos dados levantados e apresentados no Gráfico 3 foi a quantidade de artigos e periódicos de acordo com o Qualis.

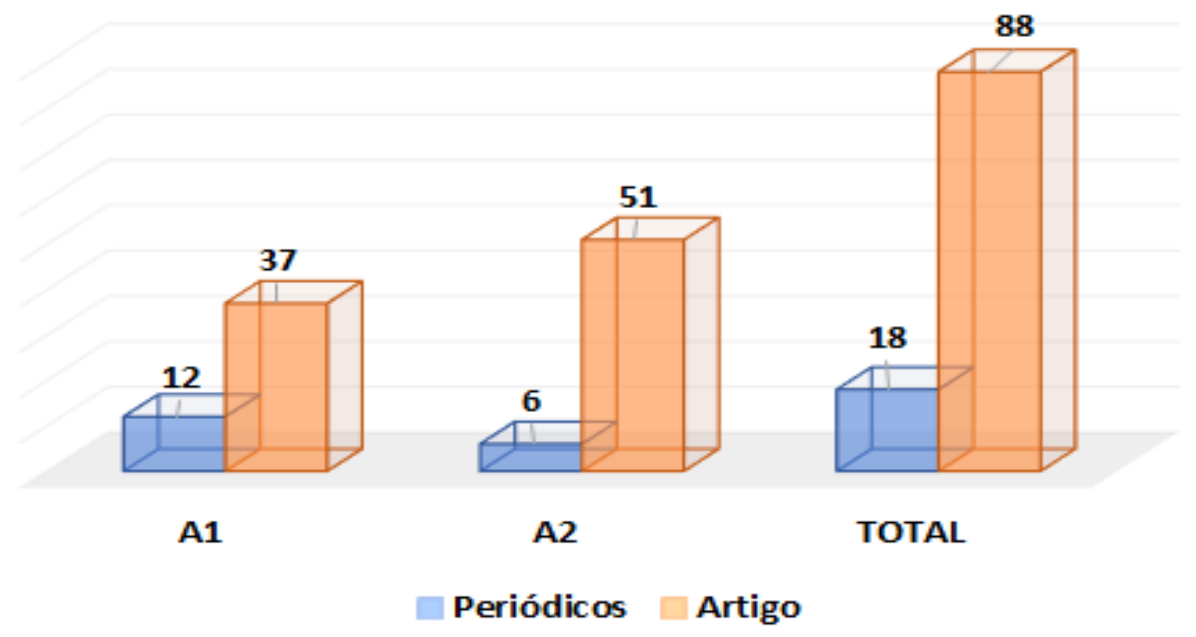

Gráfico 3: Quantidade de artigos e periódicos por Qualis.

Fonte: Dados da pesquisa (2017)

Diante desse gráfico, podemos observar que nos 12 periódicos A1 foram publicados 37 artigos, e nos seis periódicos A2 foram 51 publicações. Ou seja, mesmo que o fator de impacto de um periódico classificado com estrato A1 seja maior do que um com estrato A2, o maior número de artigos científicos levantados, no recorte temporal analisado, foi publicado nesse último estrato. A média de publicações por estrato é de 3,08 artigos em A1 e 8,5 em A2, uma diferença de 5,42 artigos por periódico.

Outro aspecto levado em consideração envolve a análise do tipo de autoria e quantidade de artigo por autor. Nesse sentido, nos 88 artigos, foi identificado um total de 140 autores e coautores. Desses autores, 14 têm destaque por publicarem mais de um artigo científico, conforme Quadro 2. 
Quadro 2: Autores mais produtivos

\begin{tabular}{|l|l|l|}
\hline Autores & $\begin{array}{l}\text { Quantidade de } \\
\text { Artigos Publicados }\end{array}$ & Percentual \\
\hline Marisa Brascher Basílio Medeiros & 6 & $14,6 \%$ \\
\hline Cristina Dotta Ortega & 5 & $12,2 \%$ \\
\hline Maria Aparecida Moura & 5 & $12,2 \%$ \\
\hline Mariangela Spotti Lopes Fujita & 4 & $9,8 \%$ \\
\hline Lígia Maria Arruda Café & 3 & $7,3 \%$ \\
\hline Brígida Maria Nogueira Cervantes & 2 & $4,9 \%$ \\
\hline Camila Monteiro de Barros & 2 & $4,9 \%$ \\
\hline Darlene Alves Bezerra & 2 & $4,9 \%$ \\
\hline Elisabete Gonçalves Souza & 2 & $4,9 \%$ \\
\hline Fabiano Ferreira de Castro & 2 & $4,9 \%$ \\
\hline Gercina Ângela Borém de Oliveira Lima & 2 & $4,9 \%$ \\
\hline Jessica Monique de Lira Vieira & 2 & $4,9 \%$ \\
\hline Luciane Paula Vital & 2 & $4,9 \%$ \\
\hline Maurício Barcellos Almeida & 2 & $4,9 \%$ \\
\hline TOTAL & $\mathbf{4 1}$ & $\mathbf{1 0 0 \%}$ \\
\hline
\end{tabular}

Fonte: Dados da pesquisa (2017)

0 total de publicações dos autores mais produtivos representa 41 artigos, que correspondem a $46,59 \%$ do total das publicações. Observa-se que entre os autores que mais publicaram sobre a temática Organização e Representação da Informação, no período de 2007 a 2016, em primeiro lugar está Marisa Brascher Basílio Medeiros (UFSC), com seis trabalhos publicados, o que corresponde a $14,6 \%$ do total das publicações. Porém, cinco desses artigos foram produzidos em coautoria, o que demonstra cooperação entre outros pesquisadores, bem como com seus orientandos.

Na sequência, têm-se Cristina Dotta Ortega (UFMG) e Maria Aparecida Moura (UFMG), com cinco trabalhos cada, escritos em sua maioria em coautoria; logo após, Mariângela Spotti Lopes Fujita (UNESP) e Lígia Maria Arruda Café (UFSC), com quatro e três trabalhos, respectivamente.

Com 2 trabalhos publicados temos: Brígida Maria Nogueira Cervantes (UEL), Camila Monteiro de Barros (UFSC), Darlene Alves Bezerra (UFF), Elisabete Gonçalves Souza (UFF), Fabiano Ferreira de Castro (UFSCAR), Gercina Ângela Borém de Oliveira Lima (UFMG), Jessica Monique de Lira Vieira (UFPE), Luciane Paula Vital (UFSC) e Maurício Barcellos Almeida (UFMG). É preciso destacar que a maioria destes autores publica em sua totalidade em coautoria.

Nessa linha de análise de participação nas produções dos artigos, verificamos o tipo de autoria que predomina nas publicações nacionais, conforme apresentado no Gráfico 3.

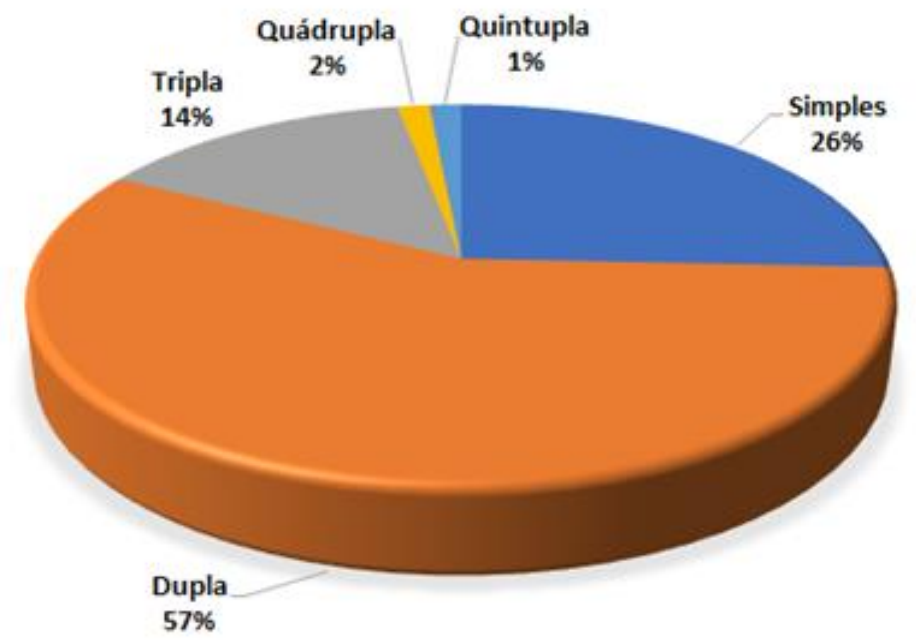

Gráfico 4: Tipo de Autoria (no Brasil)

Fonte: Dados da pesquisa (2017) 
Observa-se que 74\% dos trabalhos publicados foram desenvolvidos em colaboração científica com dois ou mais pesquisadores trabalhando em coautoria, percentual considerado significativo. As coautorias duplas (57\%) predominam nas publicações nacionais, tratandose de um indicador modal de colaboração na área em estudo, advindas de diversas possibilidades, tais como, orientador/orientando, docente/profissional, docente/docente, aluno/aluno, entre outras.

Nas publicações dos periódicos internacionais, podemos observar o contrário da realidade nacional, devido à predominância de publicações com autoria simples (44\%), conforme apresentado no Gráfico 5.

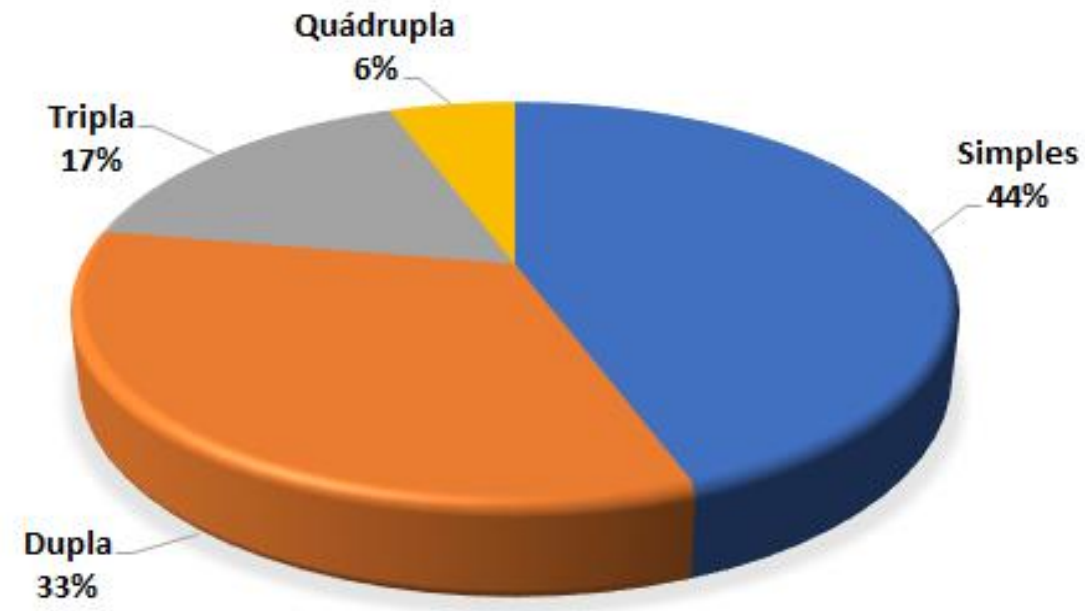

Gráfico 5: Tipo de Autoria (no Exterior)

Fonte: Dados da pesquisa (2017)

\section{CONSIDERAÇÕES FINAIS}

A presente pesquisa buscou identificar, por meio da análise bibliométrica, a produção científica brasileira sobre a temática da Organização e Representação da Informação publicada na área da Ciência da Informação.

Como resultado detectamos que, dentre os periódicos nacionais e internacionais, temos uma produção científica "doméstica", voltada em sua maioria para o próprio país. Percebemos que as principais revistas que publicam sobre a temática estudada, foram: a) Informação \& Informação (UEL); b) Encontros Bibli (UFSC); e c) Transinformação (PUCCampinas), pois os principais pesquisadores da área neste domínio têm primado por realizar a comunicação científica oriunda de suas pesquisas em revistas de alto impacto acadêmico.

0 resultado sobre os autores mais produtivos mostra um elenco de pesquisadores reconhecidos e que produzem muitas vezes em colaboração científica com outros autores. A coautoria aumenta e melhora a qualidade da produção acadêmica e possibilita o compartilhamento do trabalho que envolve todas as etapas do processo Editorial até a publicação do artigo.

Essa investigação possibilitou, a partir dos dados analisados, observar que existe um crescimento em nível nacional de estudos sobre "Organização e Representação da Informação", no que diz respeito à representatividade da temática, a partir das produções científicas de maior impacto no campo de pesquisa da Ciência da Informação. Contudo, em nível internacional, ainda existem lacunas a serem preenchidas. É importante que o elenco de autores que pesquisam sobre o tema em lide, possa ultrapassar as barreiras "domésticas" e delimitar novos espaços internacionais.

Destaca-se que a pesquisa com caráter bibliométrico é uma ferramenta estratégica para um levantamento bibliográfico de densidade e envergadura científica. Diante do contexto de volume informacional, é relevante ao profissional da informação realizar investigações periódicas no sentido de medir quantitativamente a produção científica tendo em vista apontar caminhos futuros às pesquisas no campo da Organização e Representação da Informação. 


\section{REFERÊNCIAS}

ALVARENGA, Lídia. Representação do conhecimento na perspectiva da ciência da informação em tempo e espaço digitais. Enc. Bibli: R. Eletr. Bibliotecon. Ci. Inf., Florianópolis, v. 8, n. 15, 2003. Disponível em: <https://periodicos.ufsc.br/index.php/eb/article/view/15182924.2003v8n15p18/5233>. Acesso em: 14 ago 2017.

BRASCHER, Marisa; CAFÉ, Lígia. Organização da Informação ou Organização do Conhecimento. In: ENCONTRO NACIONAL DE PESQUISA EM CIÊNCIA DA INFORMAÇ̃̃̃O, 9., 2008, São Paulo. Anais... São Paulo: ENANCIB; USP, 2008. Disponível em: <http://skat.ihmc.us/rid=1KR7TM7S9-S3HDKP5STP/BRASCHERCAF\%C3\%89>. Acesso em: 25 jun. 2017.

BUFREM, Leilah Santiago; PRATES, Yara. 0 saber científico registrado e as práticas de mensuração da informação. Ciência da Informação, Brasília, DF, v. 34, n. 2, p. 9-25, maio/ago. 2005. Disponível em: <http://www.brapci.ufpr.br/brapci/index.php/article/download/9906>. Acesso em: 18 jul. 2017.

GAUDÊNCIO, Mário; ALBUQUERQUE, Maria Elizabeth Baltar Carneiro de. Representação semânticodiscursiva de cibercordéis. Em Questão, Porto Alegre, v. 23, n. 1, p. 129-153, jan/abr. 2017. Disponível em: <http://www.seer.ufrgs.br/EmQuestao/article/view/62701>. Acesso em: 14 ago. 2017.

GIL, Antonio Carlos. Métodos e técnicas de pesquisa social. 6. ed. São Paulo: Atlas, 2014.

GONSALVES, Elisa Pereira. Conversas sobre iniciação à pesquisa científica. 5. ed. rev. e ampl. Campinas, SP: Alínea, 2011.

LIMA, José Leonardo Oliveira; ALVARES, Lillian. Organização e representação da informação e do conhecimento. In: ALVARES, Lillian (Org.). Organização e representação da informação e do conhecimento: conceitos, subsídios, interdisciplinaridades e aplicações. São Paulo: B4, 2012. cap. 1.

MARTINS, Gilberto de Andrade; THEÓPHILO, Carlos Renato. Metodologia da investigação científica para ciências sociais aplicadas. 2. ed. São Paulo: Atlas, 2009.

MENDONÇA, Marina Alves. Periódicos científicos eletrônicos nacionais de biblioteconomia e ciência da informação: estudos produzidos entre 2003 e 2013, 2015. 133 f. Dissertação (Mestrado em Ciência da Informação) - Universidade Federal da Paraíba, João Pessoa, 2015. Disponível em: $<$ http://tede.biblioteca.ufpb.br/bitstream/tede/7831/2/arquivototal.pdf >. Acesso em: 18 jul. 2017.

RUDIO, Franz Victor. Introdução ao projeto de pesquisa científica. 40. ed. Petrópolis, RJ: Vozes, 2012.

SAMPIERI, Roberto Hernándes; COLLADO, Carlos Fernández; LUCIO, María del Pilar Baptista. Metodologia da pesquisa. Tradução de Daisy Vaz de Moraes. 5. ed. Porto Alegre: Penso, 2013.

SANTOS, Raimundo Nonato Ribeiro dos; NEVES, Dulce Amélia de Brito; FREIRE, Isa Maria. Organização da informação em blogs: análise do uso de etiquetas no blog de olho na CI. PontodeAcesso, Salvador, v.11, n.1, p. 2-19, abr. 2017. Disponível em:

<https://portalseer.ufba.br/index.php/revistaici/article/view/21438/14662>. Acesso em: 18 jul. 2017.

SOUZA, Cláudia Daniele de. A organização do conhecimento: Estudo bibliométrico na base de dados ISI Web of Knowledge. Biblios, Lima, n. 51, p. 20-32, 2013. Disponível em: <https://biblios.pitt.edu/ojs/index.php/biblios/article/view/108/163>. Acesso em: 18 jul. 2017.

Editores do artigo: Enrique Muriel-Torrado, Edgar Bisset Alvarez, Camila Barros. 